\title{
Forgiveness and Forgiveness Flexibility among University Students: An Experimental Study
}

\author{
Ayca Delibalta ${ }^{1}$, Ezgi Caglar ${ }^{1, *} \&$ Sinem Evin Akbay ${ }^{1}$ \\ ${ }^{1}$ Faculty of Education, Department of Educational Sciences, Psychological Counseling and Guidance, Mersin \\ University, Mersin, Turkey \\ *Correspondence: Faculty of Education, Department of Educational Sciences, Psychological Counseling and \\ Guidance, Mersin University, Mersin, Turkey. Tel: 90-326-221-8713. E-mail: caglarezgi94@gmail.com
}

Received: May 25, 2020

Accepted: August 6, $2020 \quad$ Online Published: August 22, 2020

doi:10.5430/wje.v10n4p104

URL: https://doi.org/10.5430/wje.v10n4p104

\begin{abstract}
This study aimed to understand the effectiveness of Forgiveness Group Therapy on forgiveness and forgiveness flexibility levels among university students. 16 students who studied at Mersin University joined the study. Enright's Process Model of Psychological Forgiveness Scale was utilized when the program is designed. The group counseling program was conducted in the presence of two psychological counselors and a supervisor. The Heartland Forgiveness Scale and Forgiveness Flexibility Scale were used to gather data. The main purpose of that program was forgive to others. To analyze the effectiveness of the Forgiveness Group Counseling Therapy on forgiveness and forgiveness flexibility, the experimental design was implied. Pre and post-test were implied to two groups which were experimental and control groups. The data which collected owing to scales was analyzed by using non-parametric methods in SPSS program. The results showed that forgiveness the others and forgiveness flexibility increased for the experimental group while forgiveness of self and forgiveness of the situation wasn't.
\end{abstract}

Keywords: forgiveness, forgiveness flexibility, group counseling, university student

\section{Introduction}

\subsection{Forgiveness}

Individuals constantly interacting with each other in society may conflict by falling into disagreements from time to time. Also, they feel hard done by they have been damaged in these conflicts. Because of that, they may avoid from making contact with each other or they would like to get even with the other person. Instead of these, they would prefer forgiveness as an option (Satıc1, 2016). Forgiveness which has recently become a topic of interest in many areas is commonly defined as that an individual willingly gives up negative and harmful feelings towards himself/herself and others, and leaves that negative feelings to positive emotions (Enright 1996; McCullough, Pargament and Thoresen, 2000; Capan and Aricioglu, 2014). In reviewing of literature, researchers also mostly used definition of forgiveness which is defined by Rye and Pargament in 2002. They described forgiveness as that individual gives positive and constructive reactions to a situation which is seen as a fault rather than seeing an offender as an enemy and wishing for revenge to offender. Moreover, North (1987, p.499) claimed that forgiveness is a moral and voluntary behavior that eases to overcome with anger for a wronged person and to feel love again in a relationship with the offender. Furthermore; according to Wade, Hoyt, Kidwell, and Worthington, forgiveness is not just a reconceliation, but reconciliation is a consort to it (2014, p. 154). According to Thompson et al. (2005, p.318), forgiveness is that individuals reframe reactions to offender or situations which they feel hard done by, from negative to positive. When a person who is hard done by empathizes with the offender and realizes that everyone may make a mistake even himself/herself, s/he starts to feel positive emotions towards the offender, which is the definition of forgiveness (Worthington, 1998, p.63). Also, promoting forgiveness is easier than decreasing some negative emotions like anger and rumination (Wade at all, 2014, p.154). Apart from these explanations, Yildiz (2019, p. 44) describes forgiveness as after an interpersonal crime, to decrease avoidance and to reduct motivation of revenge. Çolakoğlu (2020, p. 13) mentions some features of forgiveness which are that forgiveness is an interpersonal structure, it is different from compromise, it is done by willingly and consciously. 
Forgiveness is a multidimensional structure consisting of emotions, thoughts, and behaviors towards one's self, others and situation. In other words, it consists of three sub-dimensions which are forgiveness of self, forgiveness of others and situations (Capan and Aricioglu, 2014). Forgiveness of self is feeling self-love and respect for himself or herself after doing something wrong. In other words, it is identified that an individual as an offender loves and respects oneself by Capan and Aricioglu (2014). It is defined as an individual's forgiveness of self, feeling positive emotions such as compassion and merciful rather than negative emotions such as anger, guilt and desire for self-punishment (Hall and Fincham, 2005; Enright and the Human Development Study Group, 1991; Enright, 1996). Forgiveness of others is defined as giving up negative feelings to the offender (Hall and Fincham, 2005). Forgiveness of situation is stated that negative emotions are given up depending on whether the circumstances are under the control of the individual or not (Thompson, et al., 2005). According to some researches, college students must get used to live separated from their family and friends, make new friends and relationships in a new environment, and maintain their emotional relationships (Capan and Aricioglu, 2014). During the university, they get pretty stressed because they start to live away from their family and adapt to a new environment (Arthur and Hiebert, 1996). Ascioglu Onal and Yalcın (2017) stated that forgiveness is accepted as an effective mechanism for dealing with this stressful mood. According to researches, university students also have some difficulties with family relationships, friendship and emotionality in Turkey (Bilgin, 2000; Erkan, Ozbay, Cankaya and Terzi, 2012). Young people who need to get closely in touch with somebody may have some problems in their emotional relationships and friendships. At the same time, they need to recompose their relationship while they are feeling independent themselves without family support. University students likely make a mistake while they are deciding about their relationships and career. In this sense, the perspectives on offense arising from themselves and their environment will also affect their forgiveness levels for others and self (Capan and Aricioglu, 2014). Therefore, university students were enrolled to the group counseling program for forgiveness in the recent study. It is predicted that group counseling program for forgiveness helps to increase forgiveness levels of university students.

\subsection{Forgiveness of Flexibility}

After a scathing issue, individuals have to decide an attitude. In order to mention the term of forgiveness after a scathing period is not enough for understanding individuals' attitudes. To understand that emotion, thought and behavior patterns should be known. In that way, after every scathing pattern, individuals' approach to forgiveness can be understood. Forgiveness flexibility is a skill which help an individual in order to decrease the negative effects of a scathing situation by using cognitive, emotional and behavioral skills (Çolak, 2014). Moreover, according to Eker (2017, p. 54), forgiveness flexibility is by deciding attitudes using all of the cognitive, emotional and behavioral skills when there is an hurtful event. Furhermore, Çolak (2014) explains that forgiveness flexibility is to prefer forgiveness by considering the individual's capacity of emotional, cognitive and behavioral areas and using it in the right way, right time and right place. According to Çolak (2014, p. 79), forgiveness flexibility has two dimensions which are forgiveness and flexibility. While forgiveness includes knowing what is forgiveness, flexibility contains to have the skills related to forgiveness and to know when, where and how he/she can use these skills (Colak, 2014). In light of this explanation, it is clear that it is not enough to know what forgiveness is. Individuals need to possess some skills so as to learn to forgive in every scathing issue. Forgiveness flexibility explains individuals' skills for forgiveness. Individuals who have forgiveness flexibility can adapt to their normal life after the scathing issue (Colak, 2014, p.80). To have flexible attitudes after a scathing issue helps individuals not only to decrease negative effects of situations in their life but also to increase the positives at the same time (Colak, 2014, p.80). According to some researches, university students must get used to live separated from their family and friends, make new friends and relationships in a new environment, and maintain their emotional relationships (Capan and Aricioglu, 2014). During the university, they get pretty stressed because they start to live away from their family and adapt to a new environment (Arthur and Hiebert, 1996). Ascioglu Onal and Yalcin (2017) stated that forgiveness is accepted as an effective mechanism for dealing with this stressful mood. According to researches, that students also have some difficulties about family relationships, friendship and emotionality in Turkey (Bilgin, 2000; Erkan, Ozbay, Cankaya and Terzi, 2012). Young people who need to get closely in touch with somebody may have some problems in their emotional relationships and friendships. At the same time, they need to recompose their relationship while they are feeling independent themselves without the family support. University students likely make a mistake while they are deciding about their relationships and career. In this sense, the perspectives on offense arising from themselves and their environment will also affect their forgiveness levels for others and self (Capan and Arıc1oglu, 2014). Therefore, they were enrolled to the group counseling program for forgiveness in the recent study. It is predicted that group counseling program for forgiveness helps to increase forgiveness levels of university students. 


\subsection{Explore Importance of the Problem}

Forgiving people take a bright view of their life and themselves with getting rid of their negative emotions and focusing on positive emotions. As they focus on the positive, they are healthfully capable of coping with the hazardous situation and can easily adapt to new situations. Furthermore, forgiveness helps not only decreasing negative emotions but also increasing positive ones on individuals. Consequently, it also ensures to increase the resilience of forgivers (Capan and Arıcioglu, 2014). In terms of psychological science, it is realized that forgiveness is related to many psychological areas in the last two decades (Bilekli, 2016). Also, there are extensive researches on the positive effects of forgiveness for the individual (Hall and Finchman, 2005). Exline and Baumeister (2000) asserted that forgiveness is greatly helpful in terms of physical and mental for the person who forgives. In addition, it gives the person psychological and mental maturity and contributes to the recent development of life skills (Hope, 1987). It helps couples to enhance the satisfaction of their relationships (McCullough et al., 1998), and people to accept them as they are (Aschleman, 1996). It also affects positively their physical health (Huang and Enright, 2000). The fact that it affects both people physically and psychologically shows that this concept is an important source of psychological power. That's why some researchers suggest that the concept of forgiveness is needed to be investigated for the literature of psychology in Turkish society (Tunca and Durmus, 2018). In the recent study, all participants had some difficulties to forgive others. They needed to forgive their offenders who are someone else. When the literature is reviewed, it was found that forgiveness of others has important roles for the individual. Some investigators stated that forgiving others helps people to get less psychological stress (Maltby, Macaskill, and Day 2001; Toussaint, Williams, Musick, and Everson, 2001). Also, individuals who are able to forgive others may have strong social ties in daily life and may exchange negative beliefs and behaviors to positive and beneficial ones (Krause and Ellison, 2003). As a result of a study, individuals who forgive others have a tendency to struggle beneficially their psychological health and life satisfaction (Toussaint et al. 2001). During the forgiveness of others, Braithwaite, Fincham and Lambert (2009) think that thoughts about characteristics of offense and how the offense is perceived by an individual affect the forgiveness of others in the process of forgiveness. However, Bugay and Demir (2016a) found that characteristics of the offense less predicted to the level of forgiveness of university students. Another result of the study is that their level of forgiveness is affected respectively by responsibility on the offense, consequences caused by the offense, and it was made by whom. Bugay and Demir (2016b) aimed to create a group counselling program to improve the forgiveness of university students themselves and others and to test the effectiveness of the program. In that study, it was found that the group counseling programs for development of forgiveness positively increased the students and the general forgiveness tendencies of the students in the experimental group. Lastly, the results of research with university students show that rumination has a mediating role in the relationship between forgiveness of self and forgiveness of others, and life satisfaction (Bugay and Demir, 2011). In the study, the aim is to understand forgiveness group therapy's effectiveness on forgiveness and forgiveness flexibility.

\subsection{State Hypothesis}

The hypothesis of the study is that "Forgiveness Improvement Group Counseling Program" has a significant effect on forgiveness and forgiveness flexibility levels of university students. It was also examined whether this hypothesis differs when analyzed by each forgiveness sub-dimensions which are self- forgiveness, forgiveness of others and situations or not.

\section{Method}

\subsection{Participant (Subject) Characteristics}

Both of experimental and control groups' members are undergraduate and graduate students at Mersin University. The study was conducted with 16 volunteer female university students, 8 of whom were experimental groups and 8 of them were controls.

\subsection{Sampling Procedures}

First of all, in order to identify participants a poster, which includes information about the forgiveness group counseling program and contact address for pre-session, was prepared. The posters that were prepared posted someplace on the campus after taking permission from the related units. The students who wanted to join the group sessions reached counselors by sending an e-mail by using the contact address that was written in the posters. Then, by making pre-sessions with these students, the participants were decided. In the pre-sessions, the information which was about forgiveness group, group rules, sessions and recoding were given by counselors. After that, they were 
separated two groups as experiment group and control group. Before starting the sessions, Heartland Forgiveness Scale and Forgiveness Flexibility Scale were implied for both groups. When they who were in the experimental group participated the sessions for 8 weeks, the students who were in the control group faced with any application.

Table 1. Mann-Whitney U Test Results for Experimental and Control Groups Pre-Test Scores

\begin{tabular}{|c|c|c|c|c|c|c|}
\hline Groups & & $\mathrm{n}$ & Mean Rank & Sum of Ranks & $\mathrm{U}$ & $\mathrm{p}$ \\
\hline Experimental & Forgiveness of Self & 8 & 7.50 & 60.00 & 24.00 & .398 \\
\hline Control & & 8 & 9.50 & 76.00 & & \\
\hline Experimental & Forgiveness of Others & 8 & 8.31 & 66.50 & 60.50 & .874 \\
\hline Control & & 8 & 8.69 & 69.50 & & \\
\hline Experimental & Forgiveness of Situation & 8 & 8.13 & 65.00 & 29.00 & .749 \\
\hline Control & & 8 & 8.88 & 71.00 & & \\
\hline Experimental & Total Forgiveness & 8 & 7.69 & 61.50 & 25.50 & .495 \\
\hline Control & & 8 & 9.31 & 74.50 & & \\
\hline Experimental & Forgiveness Flexibility & 8 & 7.63 & 61.00 & 25.00 & .461 \\
\hline Control & & 8 & 9.38 & 75.00 & & \\
\hline
\end{tabular}

Before starting the sessions, the data which obtained were analyzed with a view to understand whether there is a difference between pre-test of experimental and control groups. Mann-Whitney $U$ analysis was conducted to test whether there was initial difference between the experimental and control group students in terms of Heartland Forgiveness and Forgiveness Flexibility Scales pre-test scores. In Table 1, it is understood that the experimental and control group students do not differ significantly from each other in terms of pre-test results related to Heartland Forgiveness and Forgiveness Flexibility Scales and can be accepted as equivalent.

\subsubsection{Instruments}

\subsubsection{Heartland Forgiveness Scale}

The scale which was developed by Thompson, Snyder, Hoffman, Michael, Rasmussen and Billings (2005) has 18 items with 7 point scale. The scale has three sub-dimensions as forgiveness of others, forgiveness of self and forgiveness a situation. In the validity and reliability studies about the test shows that Heartland Forgiveness Scale's correlation as self, other, the situation is $.72, .73, .77$ and .83 . The Turkish form of the scale that was adapted by Bugay and Demir (2010a) was used in this study. The Cronbach $\alpha$ of the Turkish form of the scale was .81. The value was found for the forgiveness of self, as .64, for the forgiveness of others as .79 , for the forgiveness of a situation as a .76. Descriptive and Confirmatory Factor Analysis values for Turkish sample were found to be sufficient.

\subsubsection{Forgiveness Flexibility Scale}

The scale, which was developed by Colak (2014), has 15 items with a 7-point scale. The scale has 3 sub-dimensions which are recognition $(1,5,8,12)$, internalization $(2,3,6,7,14)$ and application $(4,9,10,11,13,15)$. When individuals obtain high scores, it explains that they have a high level of forgiveness flexibility. The highest point that can be got from the scale is 75 , and the lowest point is 15 . The internal consistency of the Cronbach alpha was found .83 for the total value. It was found .76 for recognition, .70 for internalization, .70 for application. These values show that using this scale can be used for measuring Forgiveness Flexibility.

\subsubsection{Forgiveness Group Counseling Program}

While developing the problem, Enrights' Forgiveness Model was used. Also, some ice-breaker activities, questions for helping clients in order to help them to describe the meaning of forgiveness, their perceptions about forgiveness and so on were utilized. Also, the sessions include some activities that used different therapy approaches like the Cognitive-behavior approach, Gestalt approach or Family System approach used for the sessions. There were eight sessions, and every session took between 90 and $120 \mathrm{~min}$. there was no application for the control group. The program was prepared by two counselors and it was controlled by an academician. After starting the sessions, some changes were made in the program by considering group members' needs.

\subsubsection{Research Design}

The study is methodized by using a quasi-experimental design in order to explain efficiency of Forgiveness Group 
Therapy on level of forgiveness and forgiveness flexibility. The quasi-experimental design has an important place in contemporary psychological counseling designs because of that they are used to investigate the relationship in applied fields (Heppner, Wampold and Kivlighan, p. 219).

\subsubsection{Process}

The aim of the study was to examine changes on university students' forgiveness and forgiveness flexibility levels after the Forgiveness Group Counseling Program. Pre and post-test model was used for the study. In order to reach students, the posters were prepared. The group was administered by two counselors and an academician who was helped counselors by supervising them. The group was only about forgiveness to others. So, it does not include forgiveness to self and forgiveness to an event. While the experimental group participates sessions, there was no application on the control group. There were no students who gave up the sessions in the experimental group. The sessions were recorded by using a video camera from the first session to the last session. All sessions were watched by two counselors and a supervisor to make changes in the next sessions.

In the session, the first goal was clarifying of the meaning of forgiveness. That is why people need to understand forgiveness if they would like to forgive something scathing. Moreover, the other aim was supplying clients ' awareness about people they want to forgive. By touching on cognitional, emotional and behavioral dimensions, clients 'awareness were increased.

In the first session, the members of the group introduced themselves. Then, group rules were shaped, and informed consent was signed. The aim of the group was mentioned, and also the expectations of the clients from the sessions were explained. By using icebreaker activity, the counselors helped clients to feel more comfortable in the session. After that, by mentioning metaphors, novels, poetries, films which are related to forgiveness, it was supplied to start the topic. Moreover, the clients mentioned personality characteristics that make forgiveness easier and harder. Lastly, the session was summarized.

The second session's aim was helping clients to understand forgiveness meaning and awareness of their thoughts, emotions and behaviors about people they want to forgive. By this aim, it started with some cards that include different explanations made by academicians about forgiveness. Also, by asking some questions, counselors helped clients for discovering their emotions, thoughts and behaviors.

In the third session, the aim was helping clients to discover deep emotions about issues they brought to sessions. With this aim, the imagination activity was done. It was asked by clients to imagine their experiences and focusing their bodies and feelings. By using a human body picture, clients mark wherever they feel something during the imagination technique. Furthermore, that paper which includes an emotion list were given to clients and asked to mark emotions they feel during the activity. In that way, clients discover some emotions they did not realize before. After these activities, the issues they suffer from started to talk. This talking includes the person they hurt, how many degrees they hurt (from 0 to 10 ), how long ago they hurt. With this talking, clients started to understand other clients' issues, and that provide group cohesion and trust.

In the fourth session, the aim was to ensure the transition to the working phase. With this aim, a house activity was used. In that activity, it was asked to clients separate the issue three parts: the part they cannot change, the part they have already solved and the part they need to work on for forgiveness. In that activity, the aim was discovering that event cannot change, we as individuals need to change our perspectives, thoughts and accept the event which happened in order to forgive the others. The whole session passed with this activity, and clients were prepared for the working phase.

The goal of the fifth session was to understand that the guilty person is a human, so even if he/she did something wrong, s/he has some positive features, too. In that though, the aim was to avoid clients in order to think negatives about issue and person. In the session, some questions asked to clients for the aim. These questions were 1) what do you think about the guilty person's childhood life? 2) Could a person's life or experiences have affected their behaviors? 3) What could be the reason for the behavior s/he did to you? 4) Is there any positive feeling you feel about this person?

The aim of the sixth session was starting to provide forgiveness. In that session, it was mentioned spiritual needs to forgive, showing compassion to this person, accepting the event and all feelings about the issue. In that session, clients tried to find new ways to overcome the events. Also, they give some suggestions to each other. It was an important step to accept events and people.

The seventh session's aim was to evaluate past, the counseling process and the future plan. An activity related to aim was done. Clients considered their improvement about the forgiveness process, and also they mentioned what they 
can do about this issue in the future. Apart from that, they touched upon the sessions 'effect on their relationships. Furthermore, it was touched on what can they do if yet face with similar issue in the future.

Last week aim was finishing sessions and was ensuring a beautiful separation. Firstly, the session was started with a double chair technique. Thanks to that technique, clients confronted the people who hurt themselves. After that, it was mentioned what they gain by the dint of the group. Also, it explained their awareness about issues they brought, changing their thoughts and emotions about issues. Additionally, in the last session, clients evaluated the group process in writing. After that, clients and counselors say goodbye to the group.

\section{Results}

In this section, the findings regarding the difference between the pretest, posttest and follow-up scores of the Heartland Forgiveness and Forgiveness Flexibility scales of the Experimental and Control groups are given.

The mean and standard deviation values of Heartland Forgiveness and Forgiveness Flexibility pre-test and post-test scores of the experimental group students were determined and then Wilcoxon Test was applied to understand whether the difference between the two averages taken from the related sample was significant. The results of these tests are given in Table 2. When Table 2 is examined, as a result of the Wilcoxon Signed Ranks Test, which is used to test whether there is a significant difference between the pre-test and post-test scores of the experimental group from the Heartland Forgiveness and Forgiveness Flexibility Scales; forgiveness of self $(z=-2.207 ; p<.05)$, forgiveness of others $(\mathrm{z}=-2.380 ; \mathrm{p}<.05)$, forgiveness of situation $(\mathrm{z}=-2.524 ; \mathrm{p}<.05)$, total forgiveness $(\mathrm{z}=-2.52 ; \mathrm{p}<.05)$ and forgiveness flexibility $(\mathrm{z}=-2.371 ; \mathrm{p}<.05)$. In the light of these findings, it can be said that there was an increase in the levels of forgiveness and forgiveness of the Experimental group after the group process.

Table 2. The Results of Wilcoxon Signed Rank Test in Terms of the Experimental Group's Pre-Test and Post-Test Scores

\begin{tabular}{|c|c|c|c|c|c|c|}
\hline Pre-Test / Post-Test & & $\mathrm{n}$ & Mean Rank & Sum of Ranks & $\mathrm{z}$ & $\mathrm{p}$ \\
\hline Negative Ranks & Forgiveness of Self & 0 & .00 & .00 & -2.207 & $.027 *$ \\
\hline Positive Ranks & & 6 & 3.50 & 21.00 & & \\
\hline Ties & & 2 & & & & \\
\hline Negative Ranks & Forgiveness of Others & 1 & 1.00 & 1.00 & -2.380 & $.017^{*}$ \\
\hline Positive Ranks & & 7 & 5.00 & 35.00 & & \\
\hline Ties & & 0 & & & & \\
\hline Negative Ranks & Forgiveness of Situation & 0 & .00 & .00 & -2.524 & $.012 *$ \\
\hline Positive Ranks & & 8 & 4.50 & 36.00 & & \\
\hline Ties & & 0 & & & & \\
\hline Negative Ranks & Total Forgiveness & 0 & .00 & .00 & -2.521 & $.012 *$ \\
\hline Positive Ranks & & 8 & 4.50 & .36 & & \\
\hline Ties & & 0 & & & & \\
\hline Negative Ranks & Forgiveness Flexibility & 0 & .00 & .00 & -2.371 & $.018^{*}$ \\
\hline Positive Ranks & & 7 & 4.00 & .28 & & \\
\hline Ties & & 1 & & & & \\
\hline
\end{tabular}

Wilcoxon Signed Rank Test was used to understand whether the difference between the Heartland Forgiveness and Forgiveness Flexibility pre and post-test scores of them in the control group was significant. The results of these tests are given in Table 3. As seen in Table 3, the control group's forgiveness of self $(\mathrm{z}=-2.386 ; \mathrm{p}<.05)$ and total forgiveness $(\mathrm{z}=-2.028 ; \mathrm{p}<.05)$ between the pre and post-test scores obtained from the Heartland Forgiveness Scale and there seems to be a significant difference. There is no statistically significant difference between forgiveness of others, forgiveness of situation and forgiveness flexibility. 
Table 3. The Results of Wilcoxon Signed Rank Test in Terms of the Control Group's Pre-Test and Post-Test Scores

\begin{tabular}{|c|c|c|c|c|c|c|}
\hline Pre-Test / Post-Test & & $\mathrm{n}$ & Mean Rank & Sum of Ranks & $\mathrm{z}$ & $\mathrm{p}$ \\
\hline Negative Ranks & Forgiveness of Self & 1 & 1.00 & 1.00 & -2.386 & $.017 *$ \\
\hline Positive Ranks & & 7 & 5.00 & 35.00 & & \\
\hline Ties & & 0 & & & & \\
\hline Negative Ranks & Forgiveness of Others & 3 & 3.17 & 9.50 & -1.199 & .230 \\
\hline Positive Ranks & & 5 & 5.30 & 26.50 & & \\
\hline Ties & & 0 & & & & \\
\hline Negative Ranks & Forgiveness of Situation & 2 & 1.75 & 3.50 & -1.472 & .141 \\
\hline Positive Ranks & & 4 & 4.38 & 17.50 & & \\
\hline Ties & & 2 & & & & \\
\hline Negative Ranks & Total Forgiveness & 1 & 2.00 & 2.00 & -2.028 & $.043^{*}$ \\
\hline Positive Ranks & & 6 & 4.33 & 26.00 & & \\
\hline Ties & & 1 & & & & \\
\hline Negative Ranks & Forgiveness Flexibility & 4 & 4.50 & 18.00 & .00 & 1.000 \\
\hline Positive Ranks & & 4 & 4.50 & 18.00 & & \\
\hline Ties & & 0 & & & & \\
\hline
\end{tabular}

Table 4. Mann-Whitney U Test Results for Experimental and Control Groups’ Post-Test Scores

\begin{tabular}{|c|c|c|c|c|c|c|}
\hline Groups & & $\mathrm{n}$ & Mean Rank & Sum of Ranks & $\mathrm{U}$ & $\mathrm{p}$ \\
\hline Experimental & Forgiveness of Self & 8 & 9.00 & 72.00 & 28.00 & .673 \\
\hline Control & & 8 & 8.00 & 64.00 & & \\
\hline Experimental & Forgiveness of Others & 8 & 11.25 & 90.00 & 10.00 & $.020^{*}$ \\
\hline Control & & 8 & 5.75 & 46.00 & & \\
\hline Experimental & Forgiveness of Situation & 8 & 10.69 & 85.50 & 14.50 & .064 \\
\hline Control & & 8 & 6.31 & 50.50 & & \\
\hline Experimental & Total Forgiveness & 8 & 11.00 & 88.00 & 12.00 & $.035^{*}$ \\
\hline Control & & 8 & 6.00 & 48.00 & & \\
\hline Experimental & Forgiveness Flexibility & 8 & 11.88 & 95.00 & 5.00 & $.004^{*}$ \\
\hline Control & & 8 & 5.13 & 41.00 & & \\
\hline
\end{tabular}

The mean and standard deviation values of the post-test scores of the Heartland Forgiveness Scale of the experimental and control groups were determined, and whether the difference between the scores obtained from the two unrelated samples was significant was tested and the results were given in Table 4 . When Table 4 is examined, according to the post-test scores of the experimental and control groups, the students participating in the group process and the students who did not participate, forgiveness of others $(U=10.00 ; p<.05)$, total forgiveness $(U=$ $12.00 ; \mathrm{p}<.05)$ and forgiveness flexibility $(\mathrm{U}=5.00 ; \mathrm{p}<.05)$ statistically significant difference was found between the scores of in favor of the experimental group. In terms of forgiveness of self and forgiveness of situation scores, there are no differences between the experimental and control groups. As a result, it is seen that the forgiveness development group has a positive effect on the forgiveness of others and the total forgiveness levels with forgiveness flexibility among university students.

After the follow-up study on the experimental and control groups, Friedman test was performed to see the difference between the pre and post-test, and follow-up scores from the Heartland Forgiveness and Forgiveness Flexibility Scales. The results of the test are given in Table 5. As seen in Table 5, the experimental group's forgiveness of self $\left(\mathrm{X}_{(\mathrm{sd}=2, \mathrm{n}=8)}=7.517, \mathrm{p}<.05\right)$, forgiveness of others $\left(\mathrm{X}_{(\mathrm{sd}=2, \mathrm{n}=8)}^{2}=5.067, \mathrm{p}<.05\right)$, forgiveness of situation $\left(\mathrm{X}_{(\mathrm{sd}=2, \mathrm{n}=8)=}\right.$ $12.452, \mathrm{p}<.05)$, total forgiveness $\left(\mathrm{X}_{(\mathrm{sd}=2, \mathrm{n}=8)}^{2}=9.250, \mathrm{p}<.05\right)$ and forgiveness flexibility $\left(\mathrm{X}_{(\mathrm{sd}=2, \mathrm{n}=8)}^{2}=11.400, \mathrm{p}<.05\right)$ were found that there was a significant difference between the rank averages of the pre and post-test, and follow-up scores. According to this result, it was determined that the forgiveness development group increased the level of forgiveness of individuals and their forgiveness flexibility compared to the pre-implementation period and this increase continued during the monitoring periods. 
Table 5. Friedman Test Results for Experimental Group's Pre-Test, Post-Test and Follow up Scores

\begin{tabular}{|c|c|c|c|c|c|c|}
\hline Subscales & Test & $\mathrm{n}$ & Mean Rank & $x^{2}$ & sd & $\mathrm{p}$ \\
\hline \multirow[t]{3}{*}{ Forgiveness of Self } & Pre-Test & 8 & 1.25 & 7.517 & 2 & $.023 *$ \\
\hline & Post-Test & 8 & 2.31 & & & \\
\hline & Follow Up & 8 & 2.44 & & & \\
\hline \multirow[t]{3}{*}{ Forgiveness of Others } & Pre-Test & 8 & 1.38 & 5.067 & 2 & $.039 *$ \\
\hline & Post-Test & 8 & 2.38 & & & \\
\hline & Follow Up & 8 & 2.25 & & & \\
\hline \multirow[t]{3}{*}{ Forgiveness of Situation } & Pre-Test & 8 & 1.00 & 12.452 & 2 & $.002 *$ \\
\hline & Post-Test & 8 & 2.44 & & & \\
\hline & Follow Up & 8 & 2.56 & & & \\
\hline \multirow[t]{3}{*}{ Total Forgiveness } & Pre-Test & 8 & 1.13 & 9.250 & 2 & $.010^{*}$ \\
\hline & Post-Test & 8 & 2.50 & & & \\
\hline & Follow Up & 8 & 2.38 & & & \\
\hline \multirow[t]{3}{*}{ Forgiveness Flexibility } & Pre-Test & 8 & 1.06 & 11.400 & 2 & $.003 *$ \\
\hline & Post-Test & 8 & 2.38 & & & \\
\hline & Follow Up & 8 & 2.56 & & & \\
\hline
\end{tabular}

$* \mathrm{P}<. \overline{05}$

\subsection{Statistics and Data Analysis}

In the analysis of the data obtained in the study, non-parametric statistics were used due to the small number of " $\mathrm{n}$ " $(<30)$. Differences between the experimental and control groups of between pre-test, post-test and follow up scores of the Heartland Forgiveness Scale and Forgiveness Flexibility Scale were tested by using Mann Whitney U Test, Wilcoxon Signed Ranks Test and Friedman Test. In the interpretation of results, the significance level which is 0.05 was taken as the upper value.

\section{Discussion}

According to the findings obtained as a result of the group counseling program prepared in order to improve the levels of the university students' tendency of forgiving others and forgiveness flexibility, it has been demonstrated that Forgiveness Group Counseling Program positively increased general and others' forgiveness and forgiveness flexibility levels of the participants in the experimental group. In other words, it was found that forgiveness of others and forgiveness flexibility levels post-test scores of participants are significantly different from each other in the experimental and control group.

First of all, there are significant differences between pre and post-test scores of forgiveness of self, forgiveness of others and situations, and forgiveness flexibility in the experimental group although it was not found the significant differences between them in the control group. Furthermore, the results of the study indicate that there is no significant difference between the experimental and control groups in terms of forgiveness of self and forgiveness of the situation. In the experimental group, it didn't occur a significant difference in the pre and post-test scores of sub-dimensions which are forgiveness of situation and self. More specifically, a group counseling program has no significant effect on the self-forgiveness and forgiveness of situation levels of the participants. On the other hand, it was found that there are significant differences between the forgiveness of others, total forgiveness and forgiveness flexibility scores of the participants when post-test scores of experimental and control groups were examined.

In other words, the forgiveness of others, total forgiveness and forgiveness flexibility levels of participants who attended the "Forgiveness Group Counseling Program" increased at the end of the group program in contrast to the control group. Lastly, the program has a positive effect on levels of forgiveness of others, total forgiveness and forgiveness flexibility among university students. As tasks of the group counseling program were prepared to improve participants' tendencies of others' forgiveness and forgiveness flexibility, that result provides evidence in the reliability of the group program. According to the analysis of the control group's scores, it has occurred that there is a significant difference between pre and post-tests scores in terms of self-forgiveness and total forgiveness while it was seen that there are no significant differences between them in terms of forgiveness of others and situations, and forgiveness flexibility. The reason is that time and personal life situations may have influenced the general and self-forgiveness scores of participants. In the study, participants were applied the scales to follow up a month later 
the program in both experimental and control groups in order to monitor and examine the reliable effects of the study. It was found that there are significant differences between pre and post-test, and follow up scores of self-forgiveness, forgiveness of others and situation, total forgiveness, and forgiveness flexibility in experimental group. According to that, "Forgiveness Group Counseling Program" has enhanced forgiveness levels and forgiveness flexibility compared to before the application of the program. Also, it seems to continue when analysis of monitoring was examined.

The forgiveness group counseling program was prepared by making use of the Enright's (1996) Forgiveness Model. It is seen that content of the model is such as to meet participants' needs in the study. During the process of Forgiveness Group Counseling Program, it was observed that the group members were very willing to participate in the activities about forgiveness in the group sessions. In addition, group members indicated that group activities and tasks, and group life were both easing forgiveness of others and providing psychological relief, which means that the Forgiveness Group Counseling Program prepared to develop forgiveness of others and forgiveness flexibility is effective. Similar to study of Bugay and Demir (2011), results of the current study emphasize that the Forgiveness Group Counseling Program increased the general forgiveness tendencies of the group members. Moreover, the finding that the forgiveness group counseling program positively affected the participants' forgiveness level is consistent with foreign literature (Rye and Pargament, 2002).

As indicated in the literature part of the study, people who forgive of others get less psychological stress than other people who do not forgive someone (Maltby, Macaskill, and Day 2001; Toussaint et al. 2001). Furthermore, they can have strong social ties in daily life and exchange negative beliefs and behaviors to positive and beneficial ones (Krause and Ellison, 2003). Furthermore, researches show that there is a significant relation between forgiveness and well-being (Akhtar, Dolan \& Barlow, 2016, p. 1). Over and above, Toussaint, Worthington, Williams \& Webb (2020) indicate that there is a relationship between forgiveness and physical health like forgiveness and psychical health. Similarly, forgiving others helps individuals to have psychological and mental maturity and contribute to the recent development of life skills (Hope, 1987). When these results are examined, it is clear that even if working on only one part of forgiveness process, people's attitudes about forgiving can be changed. In other words, people can increase their forgiveness flexibility when they experience a forgiveness process.

It is seen that forgiveness of others may have helped participants to increase forgiveness flexibility although there is no supporting research about forgiveness of flexibility in the literature. Also, the researches about forgiveness of flexibility and studies for forgiveness group counseling are limited in the literature. That's why, the recent study is considered to be helpful for psychological counseling practices. It is also considered that preparing group counseling program for forgiveness with benefit from this study may make it easier for clients to forgive others and increase forgiveness flexibility. The results of that study can contribute to the development of group counseling programs about forgiveness for psychological counselors.

\section{Conclusion}

Forgiveness is a topic that is interested in many different areas. It is described as a willingness to forego negative and harmful emotions to himself/herself, others, or an event (Enright 1996; McCullough, Pargament and Thoresen, 2000; Capan and Aricioglu, 2014). Studies explain that to forgive people need to empathise with the others, herself/himself or an event (Worthington, 1998, s.63). By empathizing people can understand everyone can make mistakes and he/she improve positive feelings towards others, herself/himself or an event. Furthermore, forgiveness flexibility is an important term which helps to understand people skills to decrease the negative effects of a scathing situation by using cognitive, emotional and behavioral skills (Çolak, 2014). In that study, it is aimed to understand whether an experience about one of the sub-dimensions of forgiveness (forgiveness of others, forgiveness to self, forgiveness of an event) can improve other sub-dimensions of forgiveness and forgiveness flexibility. In that curiosity, it is decided to do a group counseling about forgiveness to others. In that way it is aimed to understand whether a group counseling about forgiveness to others increase scores about forgiving others, forgiving self, forgiving an event and forgiveness flexibility.

The results of the study show that the program prepared for forgiveness of others helps students to positively increase general and others' forgiveness and forgiveness flexibility levels of the participants in the experimental group. In other words, post-test results for the experimental group explain that students' levels about general and others' forgiveness and forgiveness flexibility improve thanks to the group counseling program. On the other hand, there is no change to experimental group levels of self-forgiveness and forgiveness of others. That means that one of the sub-dimensions areas of forgiveness cannot enough to general it to all sub-dimensions of forgiveness. However, it 
can help people to improve their skills about forgiveness which is given by forgiveness flexibility.

\section{References}

Arthur, N., \& Hiebert, B. (1996). Coping with the transition to post-secondary education. Canadian Journal of Counselling, 30(2), 93-103.

Aschleman, K. A. (1996). Forgiveness as a resiliency factor in divorced or permanently separated families (Unpublished master's thesis). University of Wisconsin, Madison.

Ascioglu Onal, A., \& Yalcin, I. (2017). Forgiveness of Others and Forgiveness of Self: The Predictive Role of Cognitive Distortions, Empathy, and Rumination. Eurasian Journal of Educational Research, 68, 97-120. http://dx.doi.org/10.14689/ejer.2017.68.6

Bilekli, I. (2016). Investigation of Mental Contagion, Religiosity, Self-Forgiveness, Guilt and Thought- Action Blend with Obsessive Compulsive Disorder Symptoms: An Experimental Study in University Students (Master's thesis, Institute of Social Science). Retrieved from http://hdl.handle.net/11655/3654

Bilgin, M. (2000). Examining the Relationships between University Students 'Problems and Values. Journal of Cukurova University Faculty of Education.

Braithwaite, S., Fincham, F. D., \& Lambert, N. (2009). Hurt and psychological health in close relationships. In A. Vangelisti (Ed.), Feeling Hurt in Close Relationships (pp. 376-399). Cambridge: Cambridge University Press.

Bugay, A., \& Demir, A. (2010). A Turkish version of Heartland Forgiveness Scale. Procedia Social and Behavioral Sciences, 5, 1927-1931.

Bugay, A., \& ve Demir, A. (2011). The mediating role of the rumination tendency in the relationship between life satisfaction and forgiveness. XI. National Psychological Counseling and Guidance Congress, Selçuk, İzmir, October, 3-5.

Bugay, A., \& Demir, A. (2016a). Failure-related features predict forgiveness for others. Turkish Psychological Counseling and Guidance Journal, 4(35).

Bugay, A., \& Demir, A. (2016b). Can forgiveness be increased? The group for developing forgiveness. Journal of Turkish psychological counseling and guidance, 4(37), 96-106.

Capan, B. E., \& Arıcıoğlu, A. (2014). Forgiveness as a predictor of psychological resilience. E-International Journal of Educational Research, 5(4), 70-82. https:doi.org/10.19160/e-ijer.05325

Colak, T. S., \& Koc, M. (2016). Forgiveness Flexibility. International Journal of Psychology and Educational Studies. 3(1), 14-30. http://dx.doi.org/10.17220/ijpes.2016.01.002

Colak, T. S. (2014). The effect of Logotherapy oriented group counselling on gaining forgiveness flexibility. (Unpublished Doctoral Dissertation). Sakarya University, Turkey.

Eker, H. (2017). The Effect Of Cognitıve Behavioral Oriented Group Counseling Applicatıon, Which Aims To Gain Forglveness Flexibility, On Hopelessness In Adolescents. (Unpiblished Master Thesis). Sakarya University. Sakarya, Turkey.

Enright, R. D. (1996). Counseling within the forgiveness triad: On forgiving, receiving forgiveness, and Forgiveness of Self. Counseling and Values, 40(2), 107-126. https://doi.org/10.1002/j.2161-007X.1996.tb00844.x

Enright, R. D. (1991). The moral development of forgiveness. In W. Kurtines \& J. Gewirtz (Eds.), Handbook of moral behavior and development (Vol. 1, pp. 123-152). Hillsdale, NJ: Erlbaum.

Erkan, S., Ozbay, Y., Cihangir-Cankaya, Z., \& Terzi, S. (2012). University students 'problem areas and psychological help-seeking willingness. Education and Science, 37(164), 94-107.

Exline, J. J., \& Baumeister, R. F. (2000). Expressing forgiveness and repentance. In M. E. McCullough, K. I. Pargament, \& ve C. E. Thoresen, (Eds.), Forgiveness: Theory, research, and practice (pp. 133- 155). New York: Guilford Publications.

Hall, J. H., \& Fincham, F. D. (2005). Self-forgiveness: The stepchild of forgiveness research. Journal of Social and Clinical Psychology, 24(5), 621-637. https://doi.org/10.1521/jscp.2005.24.5.621

Hope, D. (1987). The healing paradox of forgiveness. Psychotherapy, 24(2), 240-244. https://doi.org/10.1037/h0085710 
Huang, S. T., \& Enright, R. D. (2000). Forgiveness and anger-related emotions in Taiwan: Implications for Therapy. Psychotherapy, 37(1), 171-179. https://doi.org/10.1037/h0087831

Krause, N., \& Ellison, C. G. (2003). Forgiveness by God, forgiveness of others, and psychological well-being in late life. Journal for the Scientific Study of Religion, 42(1), 77-93. https://doi.org/10.1111/1468-5906.00162

Maltby, J., Macaskill, A., \& Day, L. (2001). Failure to forgive self and others: A replication and extension of the relationship between forgiveness, personality, social desirability, and general health. Personality and Individual Differences, 30, 881-85. https://doi.org/10.1016/S0191-8869(00)00080-5

McCullough, M. E., Pargament, K. I., \& Thoresen, C. E. (2000). Forgiveness: Theory, Research and Practice. New York: Guilford Press.

McCullough, M. E., Rachal, K. C., Sandage, S. J., Worthington, E. L., Brown, S. W., \& Hight, T. L. (1998). Interpersonal forgiving in close relationship II: Theoretical elaboration and measurement. Journal of Personality and Social Psychology, 75(6), 1586-1603. https://doi.org/10.1037/0022-3514.75.6.1586

North, J. (1987). Wrongdoing and forgiveness. Philosophy, 42, 499-508. https://doi.org/10.1017/S003181910003905X

Reisoğlu, G. (2020). The Relatıonship Between Satısfactıon In Romantıc Relatıonship, Beliefs Related To Forgiveness And Forgiveness. (Unpublished Master Thesis). Gaziantep University. Gaziantep, Turkey.

Rye, M. S., \& Pargament, K. I. (2002). Evaluation of a secular and religiously integrated forgiveness group therapy program for college students who have been wronged by a romantic partner. Journal of Clinical Psychology, 58 , 419-441.

Satıc1, S. A. (2016). University Students' Forgiveness, Revenge, Social Commitment and Subjective Well-Being: A Study on Testing Different Structural Models (Unpublished doctoral dissertation). Eskisehir: Anadolu University.

Thompson, L. Y., Snyder, C. R., Hoffman, L., Michael, S. T., Rasmussen, H. N., Billings, L. S., \& Roberts, D. E. (2005). Dispositional forgiveness of self, others, and situations. Journal of Personality, 73(2), 313-360. https://doi.org/10.1111/j.1467-6494.2005.00311.x

Toussaint, L. L., Williams, D. R., Musick, M. A., \& Everson. S. A. (2001). Forgiveness and health: Age differences in a U.S. probability sample. Journal of Adult Development, 8, 249-257. https://doi.org/10.1023/A:1011394629736

Toussaint, L. L., Worthington, E. L., Williams, D. R., \& Webb, J. R. (2019). Forgiveness and Physical Health. Handbook of Forgiveness. New York. https://doi.org/10.4324/9781351123341 1

Tunca, A., \& Durmus, E. (2018). The Relationship between Perceived Parents' Attitudes and Forgiveness Levels of University Students. OPUS International Journal of Community Research, 9(16), 524-550. https://doi.org/10.26466/opus.470406

Worthington, E. L. (1998). An empathy-humility-commitment model of forgiveness applied within family dyads. Journal of Family Therapy, 20, 59-76. https://doi.org/10.1111/1467-6427.00

Yldiz, B. (2019). The Predictive Roles of Self-Differentiation and Forgiveness on Rumination. Eva Academi Journal, 80(23), 41-56.

\section{Copyrights}

Copyright for this article is retained by the author(s), with first publication rights granted to the journal.

This is an open-access article distributed under the terms and conditions of the Creative Commons Attribution license (http://creativecommons.org/licenses/by/4.0/). 